OPEN ACCESS

Edited by:

Learn-Han Lee,

Monash University Malaysia,

Malaysia

Reviewed by:

Qingping Zhong,

South China Agricultural University,

China

Iddya Karunasagar,

Nitte University, India

Veronica Lazar,

University of Bucharest, Romania

Mariana Carmen Chifiriuc,

University of Bucharest, Romania

*Correspondence:

Chao Shi

meilixinong@nwsuaf.edu.cn

Specialty section:

This article was submitted to

Food Microbiology,

a section of the journal

Frontiers in Microbiology

Received: 17 October 2018

Accepted: 08 April 2019

Published: 25 April 2019

Citation:

Sun Y, Guo D, Hua Z, Sun $H$,

Zheng Z, Xia $X$ and Shi $C$

(2019) Attenuation of

Multiple Vibrio parahaemolyticus

Virulence Factors by Citral.

Front. Microbiol. 10:894.

doi: 10.3389/fmicb.2019.00894

\section{Attenuation of Multiple Vibrio parahaemolyticus Virulence Factors by Citral}

\author{
Yi Sun ${ }^{1}$, Du Guo ${ }^{1}$, Zi Hua ${ }^{1}$, Huihui Sun ${ }^{1}$, Zhanwen Zheng ${ }^{1}$, Xiaodong Xia ${ }^{1,2}$ and Chao Shi* \\ ${ }^{1}$ College of Food Science and Engineering, Northwest A\&F University, Yangling, China, ${ }^{2}$ Sino-US Joint Research Center for \\ Food Safety, Northwest A\&F University, Yangling, China
}

Citral was known as a widely used food additive with antimicrobial activity; however, whether it can be a potential therapy for controlling bacterial virulence with less risk of antimicrobial resistance remains to be investigated. Herein, we demonstrated that Vibrio parahaemolyticus virulence factors that contribute to infection were effectively inhibited to different degrees by sub-inhibitory concentrations $(3.125,6.25$, and $12.5 \mathrm{\mu g} / \mathrm{ml}$ ) of citral. Citral exerted strong inhibition of autoinducer-2 production and adhesion to Caco-2 cells. Biofilm formation of $V$. parahaemolyticus was effectively decreased by citral at $30^{\circ} \mathrm{C}$ and $20^{\circ} \mathrm{C}$. Moreover, citral repressed the transcription of genes related to flagella biosynthesis, biofilm formation, type III secretion effectors, and antibiotic resistance, as well as genes contributing to the regulation of quorum sensing and toxin production. Therefore, citral could effectively attenuate multiple virulence properties of $V$. parahaemolyticus, and its effect on in vivo infection by $V$. parahaemolyticus needs further investigation.

Keywords: citral, Vibrio parahaemolyticus, quorum sensing, biofilm, anti-virulence

\section{INTRODUCTION}

The increasing occurrence of disease outbreaks caused by antibiotic-resistant pathogens is becoming a major cause of mortality worldwide (Letchumanan et al., 2015). Therefore, there is an urgent need to identify novel and alternative strategies to control disease outbreaks. Anti-virulence therapies aim to inhibit the specific functions of pathogens that are required to cause infection (Rasko and Sperandio, 2010). As virulence factors are not necessary for bacterial survival, anti-virulence therapies tend to be less prone to the development of resistance and have less impact on neutral and beneficial host bacteria compared with traditional antimicrobials (Rasko and Sperandio, 2010).

Vibrio parahaemolyticus is a halophilic, motile, curved gram-negative bacterium that is frequently associated with foodborne outbreaks of disease, usually following the consumption of contaminated seafood such as raw or improperly cooked shellfish and ready-to-eat foods (Wu et al., 2014; Xie et al., 2016). V. parahaemolyticus contains various virulence factors responsible for several distinct diseases, including wound infections, human acute gastroenteritis, septicemia, and even death and is therefore a significant cause for concern regarding seafood safety (Yeung et al., 2002).

The virulence factors of $V$. parahaemolyticus are complex and interactive. The bacterium readily forms biofilms on food-processing surfaces such as kitchen cutting boards and stainless steel and can adhere to human intestinal cell lines, contributing to cross-contamination and 
the ensuing diseases (Chiu et al., 2006; Mizan et al., 2016). During the establishment of infection, motility (swimming and swarming) is an important function of biofilm formation and adhesion (Zhu et al., 2013). Following intimate contact with the host cells, $V$. parahaemolyticus then secretes toxin proteins and delivers type III secretion system (T3SS) effectors into the host cell cytoplasm, inducing cytotoxicity and bacterial enterotoxicity (Makino et al., 2003; Park et al., 2004). In V. parahaemolyticus, quorum sensing (QS) is a cell-to-cell communication system that responds to fluctuations in cell population density through the secretion of autoinducer-2 (AI-2) (Mizan et al., 2016). Once AI-2 has reached a critical threshold concentration, the QS system begins to induce the expression of several virulence factors, including motility (Zhu et al., 2013), biofilm formation (Mizan et al., 2016), adhesion (LaSarre and Federle, 2013), T3SSs (Henke and Bassler, 2004), and toxin production (Zhu et al., 2002).

Essential oils have long been recognized as eco-friendly anti-microbial materials with low mammalian toxicities (Isman, 2000). Citral (3,7-dimethyl-2,6-octadienal) is the principal component of lemongrass oil and has strong antimicrobial activity (Adukwu et al., 2016). Additionally, citral is widely used as a health-promoting food additive for human and animal (FDA, GRAS, 21 CFR 182.60). Because of its strong antimicrobial activity and wide application in food products, the potential of citral to affect bacterial virulence factors should be recognized.

To date, anti-QS approach is one of the most intensively studied in anti-virulence therapies (LaSarre and Federle, 2013). In addition, therapies aimed at attenuating pili, secretion systems, or toxin production have also been reported, respectively (Rasko and Sperandio, 2010). However, the mechanism of $V$. parahaemolyticus pathogenesis is complicated and remains unclear; thus, alternative approaches that interfere with multiple virulence factors should be given more attention. The aim of the current study was to investigate the effect of citral at sub-inhibitory concentrations on the various virulence properties of $V$. parahaemolyticus. The effects of citral on QS, motility, biofilm formation, and adhesion of $V$. parahaemolyticus were investigated, and the effects of citral on the transcription of virulence-associated genes and antibiotic resistance genes were also examined.

\section{MATERIALS AND METHODS}

\section{Reagents}

Citral (CAS:5392-40-5) was obtained from the Chengdu Must Bio-technology Co., Ltd. (Chengdu, Sichuan, China) at a high-performance liquid chromatography purity of at least 99\%. The desired concentrations of citral solution were freshly prepared in $0.1 \%$ dimethyl sulfoxide before use. All other chemicals were of analytical grade and were unaltered.

\section{Bacterial Strains and Growth Conditions}

V. parahaemolyticus strains ATCC 17802 and ATCC 33847 (American Type Culture Collection, Manassas, USA) were used in this study. A further $46 \mathrm{~V}$. parahaemolyticus isolates recovered from marine products collected by the Hong Kong Polytechnic University were also included. A loopful of each strain was inoculated into $30 \mathrm{ml}$ of tryptic soy broth (TSB; Difco, Franklin Lakes, NJ, USA) containing 3\% (wt/vol) $\mathrm{NaCl}$ and incubated at $37^{\circ} \mathrm{C}$. Subsequently, the $V$. parahaemolyticus cultures were centrifuged at $8,000 \times g$ for $5 \mathrm{~min}$ at $4^{\circ} \mathrm{C}$, washed, and then re-suspended in fresh TSB $(3 \% \mathrm{NaCl})$. Vibrio harveyi strains $\mathrm{BB} 170$ and BB120 (ATCC) were used for the detection of $\mathrm{AI}-2$ in $\mathrm{QS}$ inhibition assays.

\section{Minimum Inhibitory Concentration Assay}

The minimum inhibitory concentrations (MICs) of citral against two V. parahaemolyticus ATCC strains (17802 and 33847) and four isolates were determined using the agar dilution method (Li et al., 2014). Different concentrations of citral (from 25 to $400 \mu \mathrm{g} / \mathrm{ml}$ ) were mixed with warm tryptone soya agar (TSA) supplemented with $3 \% \mathrm{NaCl}$ and transferred into sterile 24 -well plates. Aliquots $(2 \mu \mathrm{l})$ of $V$. parahaemolyticus suspension $\left(\sim 10^{5}\right.$ colony-forming units, $\left.\mathrm{CFU}\right)$ were then spotted onto the medium, and the samples were incubated at $37^{\circ} \mathrm{C}$ for $24 \mathrm{~h}$. The MIC was defined as the minimum concentration of citral at which there was no visible growth of the test strain. Kanamycin $(100 \mathrm{mg} / \mathrm{L})$ was used as a positive control. Results were calculated as a mean of experiments performed in triplicate.

\section{Sub-inhibitory Concentration Assay}

A broth dilution assay (Shi et al., 2017) with slight modifications was performed to identify the concentrations of citral that had no effect on the growth of $V$. parahaemolyticus. Equivalent volumes $(125 \mu \mathrm{l})$ of bacterial suspension $\left(\sim 10^{4} \mathrm{CFU}\right)$ and citral solution were transferred into 96-well microtiter plates to give final citral concentrations of 0 (control), 3.125, 6.25, 12.5, 25, 50,100 , and $200 \mu \mathrm{g} / \mathrm{ml}$. The samples were incubated for $24 \mathrm{~h}$ at $37^{\circ} \mathrm{C}$, and cell density was measured as optical density (OD) at $600 \mathrm{~nm}$ using an automatic growth curve analyzer (Labsystems, Helsinki, Finland). Medium without bacteria was used as the negative control. OD measurements were taken in triplicate from three independent experiments to obtain a mean value for each citral concentration.

\section{Sub-inhibitory Concentration and Autoinducer-2 Determination Assay}

To detect and quantify AI-2 production by V. parahaemolyticus, a bioluminescent bacterial reporter strain called $V$. harveyi $\mathrm{BB} 170$, which produces light in response to AI-2, was used in the assay (Han et al., 2016). The sub-inhibitory concentration (SIC) of citral for $V$. harveyi BB170 was first determined as described previously. The effect of citral on AI-2 production was then determined according to a previously described method (Han et al., 2016), with minor modifications. Briefly, a log-phase culture of $V$. parahaemolyticus ATCC 17802 was centrifuged $(8,000 \times g$, $5 \mathrm{~min}, 4^{\circ} \mathrm{C}$ ) and the cell pellet was re-suspended in TSB to an $\mathrm{OD}_{600 \mathrm{~nm}}=0.5$. The suspension was then treated with 3.125 or $6.25 \mu \mathrm{g} / \mathrm{ml}$ of citral and incubated with shaking for $6 \mathrm{~h}$ at $30^{\circ} \mathrm{C}$. Supernatant containing QS molecules was obtained by centrifuging the cultures at $8,000 \times g$ for $10 \mathrm{~min}$ at $4^{\circ} \mathrm{C}$. The supernatants 
were passed through $0.2-\mu \mathrm{m}$ Tuffryn syringe filters and stored at $-20^{\circ} \mathrm{C}$. The cell-free supernatants were then tested for the presence of autoinducers that could induce luminescence in $V$. harveyi reporter strain BB170. For this bioassay, $V$. harveyi strain $\mathrm{BB} 170$ was grown overnight at $30^{\circ} \mathrm{C}$ with aeration in autoinducer bioassay $(\mathrm{AB})$ broth and then diluted 1:1,000 in $\mathrm{AB}$ medium. Diluted strain BB170 was then added along with each individual cell-free supernatant to $50-\mathrm{ml}$ tubes and incubated for $16 \mathrm{~h}$ at $30^{\circ} \mathrm{C}$ with shaking at $180 \times g$ to allow the development of luminescence by the reporter strain. Aliquots $(100 \mu \mathrm{l})$ of each of the samples were transferred to 96-well white microtiter plates and luminescence was measured using a microplate reader (Tecan, Infinite M200 PRO, Männedorf, Switzerland). V. harveyi strain BB120 (which produces AI-1 and AI-2) was used as a positive control and was grown overnight at $30^{\circ} \mathrm{C}$ with shaking in $\mathrm{LB}$ broth, following which, $1 \mathrm{ml}$ of cell-free supernatant from the culture was prepared as described previously.

\section{Motility Assay}

Swimming and swarming motility were assessed as described by Packiavathy et al. (2012). For the swimming motility assay, $20 \mathrm{ml}$ of LB broth containing $0.3 \%$ (wt/vol) agar was used. Citral was added to the warm $\left(45^{\circ} \mathrm{C}\right)$ semi-solid agar medium to obtain final concentrations of $0,3.125,6.25$, and $12.5 \mu \mathrm{g} / \mathrm{ml}$. After being dried for $1 \mathrm{~h}$, the semi-solid agar plates were spotted with 5- $\mu$ l volumes of $V$. parahaemolyticus culture $\left(\sim 1 \times 10^{6} \mathrm{CFU}\right.$, at the center of the plate) and incubated at $37^{\circ} \mathrm{C}$ for $7 \mathrm{~h}$. To examine swarming motility, $20 \mathrm{ml}$ of LB broth was supplemented with $0.5 \%(\mathrm{wt} / \mathrm{vol})$ agar and $0.5 \%(\mathrm{wt} / \mathrm{vol})$ glucose and mixed with citral at final concentrations of $0,3.125,6.25$, and $12.5 \mu \mathrm{g} / \mathrm{ml}$. Aliquots $(5 \mu \mathrm{l})$ of bacterial culture were then stabbed into the medium and plates were incubated upside down at $37^{\circ} \mathrm{C}$ for $20 \mathrm{~h}$. The diameter of the motility area was measured using AutoCAD. Medium without citral was used as a control.

\section{Congo Red Agar Assay}

To visually detect biofilm formation by the $46 \mathrm{~V}$. parahaemolyticus isolates, a Congo red agar (CRA) assay was performed as previously described by Wojtyczka et al. (2014). The isolates were inoculated onto brain-heart infusion (BHI) agar medium supplemented with $5 \%$ (wt/vol) sucrose and Congo red, samples were incubated for $24 \mathrm{~h}$ at $37^{\circ} \mathrm{C}$. Under these conditions, biofilm producers form black crusty colonies on the CRA-BHI plates, whereas non-producers form red colonies.

\section{Crystal Violet Assay}

Biofilm formation was also examined with respect to biomass using a Crystal violet (CV) staining method described by Naves et al. (2008), with some modifications. Log-phase cultures of V. parahaemolyticus ATCC 17802, VP244, and VP253 were separately centrifuged $\left(8,000 \times g, 5 \mathrm{~min}, 4^{\circ} \mathrm{C}\right)$ and re-suspended in TSB $(3 \% \mathrm{NaCl})$. Then, $250-\mu \mathrm{l}$ aliquots of the cell suspensions $\left(\mathrm{OD}_{600 \mathrm{~nm}}=1\right)$ supplemented with citral $(0,3.125,6.25$, and $12.5 \mu \mathrm{g} / \mathrm{ml}$ ) were inoculated into sterile 96-well polystyrene tissue culture plates and incubated for 24,48 , or $72 \mathrm{~h}$ without agitation. Uninoculated LB broth was used as a control. Six wells were used per strain. At each time point, bacterial growth was determined by measuring the $\mathrm{OD}$ at $630 \mathrm{~nm}$ using a microplate spectrophotometer (model 680; Bio-Rad, Hercules, CA, USA). Growth medium was then carefully removed, and each well was rinsed once with distilled water to remove any unbound bacteria. After being air-dried for $30 \mathrm{~min}$, biofilms were stained with $250 \mu \mathrm{l}$ of $1 \%$ (wt/vol) CV solution (Tianjin Kermel Chemical Regent Co., Tianjin, China) for $20 \mathrm{~min}$ at room temperature. The $\mathrm{CV}$ dye was then discarded, and the wells were rinsed three times with distilled water to remove any unbound colorant. After drying, the stained biofilm was solubilized in $250 \mu \mathrm{l}$ of $33 \%$ ( $\mathrm{vol} / \mathrm{vol}$ ) glacial acetic acid for $20 \mathrm{~min}$ and the $\mathrm{OD}_{570 \mathrm{~nm}}$ was measured. The specific biofilm formation $(\mathrm{SBF})$ was calculated by attaching and stained bacteria $\left(\mathrm{OD}_{570 \mathrm{~nm}}\right)$ normalized with cell growth $\left(\mathrm{OD}_{630 \mathrm{~nm}}\right)$. The experiment was repeated at least three times.

\section{Field Emission Scanning Electron Microscopy}

Field emission scanning electron microscopy (FE-SEM) was used to assess the effect of citral on the biofilm morphology of V. parahaemolyticus ATCC 17802 as described previously (Li et al., 2014), with some modifications. Bacterial cells $\left(\mathrm{OD}_{600 \mathrm{~nm}}=1\right)$ were treated with citral $(0,3.125,6.25$, or $12.5 \mu \mathrm{g} / \mathrm{ml})$ and then incubated at $30^{\circ} \mathrm{C}$ for $72 \mathrm{~h}$ to allow biofilm formation on coverslips. Bacterial suspensions were removed and then the coverslips were gently washed twice with phosphate-buffered saline (PBS, $\mathrm{pH}=7.0$ ) before the addition of $2.5 \%(\mathrm{vol} / \mathrm{vol})$ glutaraldehyde and incubation overnight at $4^{\circ} \mathrm{C}$ to fix the cells. The samples were then serially dehydrated with ethanol $(30,50,70,80,90$, and $100 \%)$ for $10 \mathrm{~min}$ each. The samples were sputter-coated with gold under vacuum conditions and visualized using a scanning electron microscope (S-4800; Hitachi, Tokyo, Japan).

\section{Adhesion of Caco-2 Cells}

Human colon adenocarcinoma cell line Caco-2 was maintained in Dulbecco's Modified Eagle Medium (DMEM) (Gibco, Grand Island, NY, USA) supplemented with $10 \%$ (vol/vol) fetal bovine serum (Hyclone, Logan, UT, USA), 1\% (vol/vol) non-essential amino acids (Gibco), and $1 \%$ (vol/vol) double antibiotic solution $(100 \mathrm{U} / \mathrm{ml}$ penicillin and $100 \mu \mathrm{g} / \mathrm{ml}$ streptomycin, Hyclone). Maintenance of the cell lines and subsequent experiments were carried out at $37^{\circ} \mathrm{C}$ in a humidified atmosphere containing $5 \% \mathrm{CO}_{2}$.

To evaluate the effect of citral on the adhesion of V. parahaemolyticus ATCC 17802 to Caco-2 cells, an adhesion assay was performed as described previously (Amalaradjou et al., 2014). Caco-2 cells were seeded in 24-well tissue culture plates $\left(10^{5}\right.$ cells/well) containing supplemented DMEM and incubated for $24 \mathrm{~h}$. $V$. parahaemolyticus ATCC 17802 was grown to log phase with and without SICs of citral $(3.125,6.25$, or $12.5 \mu \mathrm{g} / \mathrm{ml})$, centrifuged, and then re-suspended in cell culture medium without antibiotics. The Caco-2 cells were rinsed then with PBS before the addition of culture medium containing the $V$. parahaemolyticus suspension $\left(10^{7} \mathrm{CFU}, \mathrm{MOI}=10\right)$. The tissue culture plates were centrifuged at $600 \times g$ for $5 \mathrm{~min}$ and incubated 
at $37^{\circ} \mathrm{C}$ in a humidified $5 \% \mathrm{CO}_{2}$ incubator for $2 \mathrm{~h}$. The culture medium was removed, then the infected monolayer cells were rinsed three times with PBS, and lysed with $0.1 \%$ Triton X-100 (Amresco, Solon, OH, USA). The number of viable adherent $V$. parahaemolyticus cells was determined by serial dilution and plating on TSA $(3 \% \mathrm{NaCl})$ plates.

\section{Quantitative Real-Time Polymerase Chain Reaction}

The effects of citral on the transcription of $V$. parahaemolyticus virulence genes (flaA, flgM, flgL, ompW, VP0950, VP0952, VP0962, $\operatorname{luxS}, \operatorname{aph} A, v o p Q, v p A 0450$, and toxR) and antimicrobial peptide
(AMP)-resistant genes (tolC, nus $A$, atp $A$, dld and $f l a$ ), were examined using a real-time quantitative polymerase chain reaction (RT-qPCR) assay. Total RNA was extracted from log-phase bacterial cultures grown with and without SICs of citral using a RNAprep Pure Bacteria Kit (Tiangen, Beijing, China) according to the manufacturer's protocol. After measuring RNA concentrations using a nucleic acid and protein spectrophotometer (Nano-200; Aosheng Instrument Co., Hangzhou, China), cDNA was synthesized using a PrimeScript RT Reagent Kit (Takara, Kyoto, Japan) according to the manufacturer's instructions. Primers used for RT-qPCR are listed in Table 1. RT-qPCR reactions were carried out in a $25-\mu$ reaction volume using SYBR Premix Ex Taq II (Takara). The thermal cycler parameters were $95^{\circ} \mathrm{C}$ for $30 \mathrm{~s}, 40$ cycles of

TABLE 1 | Effects of sub-inhibitory concentrations of citral on the transcription of virulence-associated genes and antibiotic resistance genes in Vibrio parahaemolyticus ATCC 17802.

\begin{tabular}{|c|c|c|c|}
\hline \multirow[t]{2}{*}{ Target gene } & \multirow[t]{2}{*}{ Sequence of primers $\left(5^{\prime}-3^{\prime}\right)^{c}$} & \multicolumn{2}{|c|}{ Relative gene expression } \\
\hline & & $12.5 \mu \mathrm{g} / \mathrm{ml}$ & $6.25 \mu \mathrm{g} / \mathrm{ml}$ \\
\hline \multirow[t]{2}{*}{ puvA } & F, CAAACTCACTCAGACTC & \multirow{2}{*}{1} & \multirow{2}{*}{1} \\
\hline & R, CGAACCGATTCAACAC & & \\
\hline \multirow[t]{2}{*}{ tolc } & F, CGCAACTCGTCGCCTAT & \multirow{2}{*}{$-3.05 \pm 0.41^{\star \star}$} & \multirow{2}{*}{$-1.12 \pm 0.32^{\star *}$} \\
\hline & R, TGTCTTGTTCGCTTAGTGTACCA & & \\
\hline \multirow[t]{2}{*}{ fla } & F, AGATCGGTITGGTGATGC & \multirow{2}{*}{$-1.85 \pm 0.19^{\star \star}$} & \multirow{2}{*}{$-1.17 \pm 0.03^{\star \star}$} \\
\hline & R, CGTTGGCTGTCTACTGATITAAG & & \\
\hline \multirow[t]{2}{*}{$\operatorname{atp} A$} & F, CGATGATCTATCTAAACAAGCGG & \multirow{2}{*}{$-1.46 \pm 0.43^{\star *}$} & \multirow{2}{*}{$-1.26 \pm 0.04^{\star \star}$} \\
\hline & R, TAAGTAGAATACGTCACCTGGGA & & \\
\hline \multirow[t]{2}{*}{ nusA } & F, TGTTTATCACTCGTTCTAAGCCT & \multirow{2}{*}{$-2.18 \pm 0.28^{\star \star}$} & \multirow{2}{*}{$-1.45 \pm 0.12^{\star \star}$} \\
\hline & R, GTITGTCATITGTITCACTGCG & & \\
\hline \multirow[t]{2}{*}{ flaA } & F, CGGACTAAACCGTATCGCTGAAA & \multirow{2}{*}{$-9.27 \pm 1.05^{\star \star}$} & \multirow{2}{*}{$-2.24 \pm 0.14^{*}$} \\
\hline & R, GGCTGCCCATAGAAAGCATTACA & & \\
\hline \multirow[t]{2}{*}{$f l g L$} & F, CGTCAGCGTCCACCACTT & \multirow{2}{*}{$-1.35 \pm 0.48^{\star \star}$} & \multirow{2}{*}{$-1.27 \pm 0.37^{\star \star}$} \\
\hline & R, GCGGCTCTGACTTACTGCTA & & \\
\hline \multirow[t]{2}{*}{$f l g M$} & F, CGTCAGCGTCCACCACTT & \multirow{2}{*}{$-1.57 \pm 0.48^{\star \star}$} & \multirow{2}{*}{$-1.52 \pm 0.03^{\star \star}$} \\
\hline & R, GCGGCTCTGACTTACTGCTA & & \\
\hline \multirow[t]{2}{*}{ dld } & F, TTATCCCGCATGAAGACCC & \multirow{2}{*}{$-2.06 \pm 0.07^{\star \star}$} & -1 \\
\hline & R, CCGATGATACCACCGCC & & 0.04 \\
\hline luxS & F, GGATITTGTCTGGCTITCCACTT & $2.01^{* \star}$ & \\
\hline & R, GGGATGTCGCACTGGTIITAC & \pm 2.01 & 1.41 \\
\hline ompW & F, TCGTGTCACCAAGTGTITCG & $-5.51 \pm 0.49^{\star \star}$ & $-1.38 \pm 0.12^{\star *}$ \\
\hline & R, CGTGGCTGAATGGTGTTGC & & \\
\hline vopQ & F, CCACAAGTITGCTTCGGTTAG & $-2.53 \pm 0.22^{* \star}$ & $-2.34 \pm 0.05^{\star \star}$ \\
\hline & R, GGTTCTCCTCGGTAGCCTGA & & \\
\hline vp0950 & F, GCCAAACTTCTCAAACAACA & $-10.64 \pm 0.63^{\star \star}$ & $-3.50 \pm 0.31^{\star \star}$ \\
\hline vp0952 & R, ATGAAACGCAATITACCATC & & \\
\hline & F, IAIGAIGGIGIIIGGIGC & $-2.43 \pm 0.18^{\star \star}$ & $-1.49 \pm 0.06^{\star *}$ \\
\hline vp0962 & F, GACCAAGACCCAGTGAGA & & \\
\hline & R, GGTAAAGCCAGCAAAGTT & $-5.74 \pm 0.84^{\star \star}$ & $-1.46 \pm 0.22$ \\
\hline vpA0450 & F, TTGCTGAAGGCTCTGATG & & \\
\hline & R, CTGCACTGGCTTATGGTC & $-2.19 \pm 0.51^{n}$ & $-1.93 \pm 0.19^{* \star}$ \\
\hline aphA & F, ACACCCAACCGTTCGTGATG & $38^{\star *}$ & $0 P^{\text {** }}$ \\
\hline & R, GTTGAAGGCGTTGCGTAGTAAG & $-1.21 \pm 0.00$ & $-1.111 \pm 0.02$ \\
\hline toxR & F, ACAATGACGCCTCTGCTAAT & $-2.87 \pm 0.87^{\star \star}$ & $-1.82+0.15^{\star *}$ \\
\hline & R, ACTCACCAATCTGACGGAACT & & \\
\hline
\end{tabular}

${ }^{*} p \leq 0.05 ;{ }^{* *} p \leq 0.01 ;{ }^{c}$ F, forward; $R$, reverse. 
$95^{\circ} \mathrm{C}$ for $5 \mathrm{~s}$, and $60^{\circ} \mathrm{C}$ for $30 \mathrm{~s}$, followed by dissociation steps of $95^{\circ} \mathrm{C}$ for $15 \mathrm{~s}$ and $60^{\circ} \mathrm{C}$ for $30 \mathrm{~s}$. All samples were analyzed in triplicate and normalized to the endogenous control (puvA) gene (Coutard et al., 2007). Samples were run on an IQ5 system (Bio-Rad), and the transcription of target genes versus puvA was determined as previously described (Shi et al., 2017).

\section{Statistical Analysis}

All experiments were performed at least in triplicate. Statistical analyses were performed using SPSS software (version 19.0; SPSS, Inc., Chicago, IL, USA). The data were presented as the mean values $\pm \mathrm{SD}(n=3)$ and differences between means were tested by Student's $t$-test. Differences were considered significant at $p \leq 0.05$.

\section{RESULTS}

\section{Determination of Minimum Inhibitory Concentrations}

The MICs of citral for six $V$. parahaemolyticus strains ranged from 100 to $300 \mu \mathrm{g} / \mathrm{ml}$ (Table 2). V. parahaemolyticus ATCC 17802 was the most susceptible to citral $(\mathrm{MIC}=100 \mu \mathrm{g} / \mathrm{ml})$, while the four $V$. parahaemolyticus isolates showed a three-fold higher tolerance to citral (MIC $=300 \mu \mathrm{g} / \mathrm{ml}$ ).

\section{Determination of Sub-inhibitory Concentration and Inhibition of Autoinducer-2 Quorum Sensing Signaling}

The growth of $V$. parahaemolyticus was suppressed at concentrations of citral above $12.5 \mu \mathrm{g} / \mathrm{ml}$ (Figure 1A). Therefore, $3.125,6.25$, and $12.5 \mu \mathrm{g} / \mathrm{ml}$ were chosen as the SICs for further virulence-related assays.

At concentrations below $6.25 \mu \mathrm{g} / \mathrm{ml}$, citral exhibited no inhibition of $V$. harveyi strain BB170 growth (Figure 1B). Production of AI-2 by V. parahaemolyticus ATCC 17802 was reduced by 42 and $58 \%$ following exposure to 3.125 and $6.25 \mu \mathrm{g} / \mathrm{ml}$ of citral, respectively $(p \leq 0.01)$ (Figure 1C).

\section{Inhibition of Swimming and Swarming Motility}

Citral effectively reduced the swimming and swarming motility (Figure 2) of $V$. parahaemolyticus in a concentration-dependent manner. At 6.25 and $12.5 \mu \mathrm{g} / \mathrm{ml}$, citral significantly decreased

TABLE 2 | Minimum inhibitory concentrations (MICs) of citral against different strains of Vibrio parahaemolyticus.

\begin{tabular}{llc}
\hline Strain & Origin & MICs $(\boldsymbol{\mu g} / \mathbf{m l})$ \\
\hline ATCC 17802 & Shirasu food poisoning & 100 \\
ATCC 33847 & Gastroenteritis & 150 \\
VP240 & Marine products & 300 \\
VP245 & Marine products & 300 \\
VP247 & Marine products & 300 \\
VP248 & Marine products & 300
\end{tabular}

the diameter of the swimming area by 20 and $47 \%$, respectively ( $p \leq 0.01$ ), while $3.125,6.25$, and $12.5 \mu \mathrm{g} / \mathrm{ml}$ of citral significantly decreased the swarming area by 22,35 , and $50 \%$, respectively $(p \leq 0.01)$.

\section{Reduction in Biomass}

Only two of the 46 tested marine product-derived V. parahaemolyticus isolates (VP244 and VP253) formed black crusty colonies on CRA medium, indicating biofilm formation.

The SBF of $\mathrm{VP} 253$ at $30^{\circ} \mathrm{C}$ was lower than that at $20^{\circ} \mathrm{C}$, while the other two strains (ATCC 17802 and VP244) were not affected by the temperature change (Figure 3). At concentrations of $3.125,6.25$, and $12.5 \mu \mathrm{g} / \mathrm{ml}$, citral significantly ( $p \leq 0.05)$ reduced biofilm formation by $V$. parahaemolyticus strains ATCC 17802, VP244, and VP253 at both 20 and $30^{\circ} \mathrm{C}$ in both a concentration- and time-dependent manner. Following incubation for $72 \mathrm{~h}$, citral $(12.5 \mu \mathrm{g} / \mathrm{ml})$ caused a greater decrease in $V$. parahaemolyticus ATCC 17802 biofilm density at $30^{\circ} \mathrm{C}$ (67.97\% reduction compared with no-citral control) (Figure 3D) than at $20^{\circ} \mathrm{C}(55.73 \%$ reduction) (Figure $3 \mathbf{A})$. In contrast, a greater decrease was observed for strains VP244 and VP253 at $20^{\circ} \mathrm{C}$ (Figures 3B,C) compared with at $30^{\circ} \mathrm{C}$ (Figures 3E,F).

\section{Observed Changes in Biofilm Structure Following Citral Treatment by Field Emission Scanning Electron Microscopy}

The architectural integrity of biofilm and the aggregation of cells were significantly altered following exposure to citral $(3.125,6.25$, or $12.5 \mu \mathrm{g} / \mathrm{ml}$ ) (Figure 4). Biofilm formed by V. parahaemolyticus control cultures displayed firm threedimensional, multicellular, complex, self-assembled structures that contained extracellular polymeric substances (EPS) (Figure 4A). With increasing concentrations of citral, the $V$. parahaemolyticus cells secreted a lesser amount of EPS and the biofilm structure became loose (Figures 4B,C). At a citral concentration of $12.5 \mu \mathrm{g} / \mathrm{ml}$, the biofilm structure was completely disrupted, with individual, dispersed cells (Figure 4D).

\section{Interruption of $\boldsymbol{V}$. parahaemolyticus Adhesion to Caco-2 Cells}

Citral significantly $(p \leq 0.01)$ inhibited the ability of $V$. parahaemolyticus to adhere to Caco-2 cells in a dose-dependent manner (Figure 5). The adherence of $V$. parahaemolyticus cells pre-exposed to $3.125,6.25$, or $12.5 \mu \mathrm{g} / \mathrm{ml}$ of citral was reduced by 35,59 , and $65 \%$, respectively, compared with the control $(p \leq 0.01)$.

\section{Down-regulation of Virulence-Associated Genes and Antimicrobial Peptide-Resistant Genes}

Citral downregulated the transcription of genes associated with flagella regulation ( $f l a A, f l g M$, flgL), biofilm formation (ompW, vp0950, vp0952, vp0962), QS regulation (luxS, aphA), T3SS1 (vopQ, vpA0450), toxin production (toxR), and AMP-resistant genes (tolC, nusA, atpA, dld and fla) to various degrees (Table 1). 


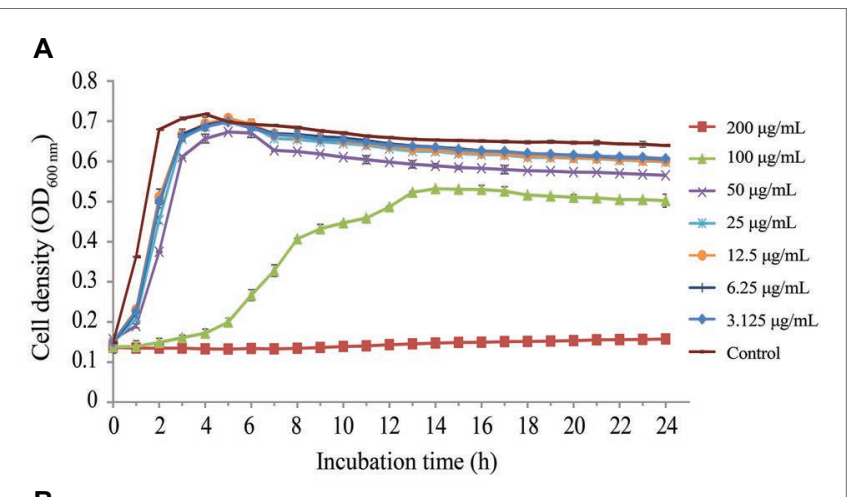

B

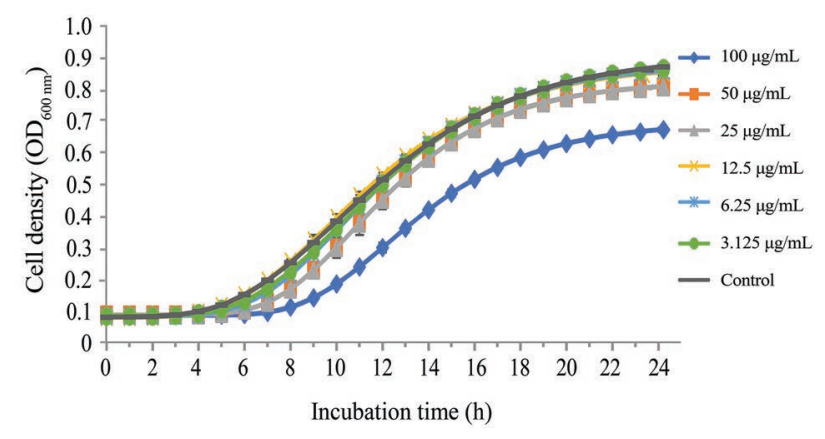

C

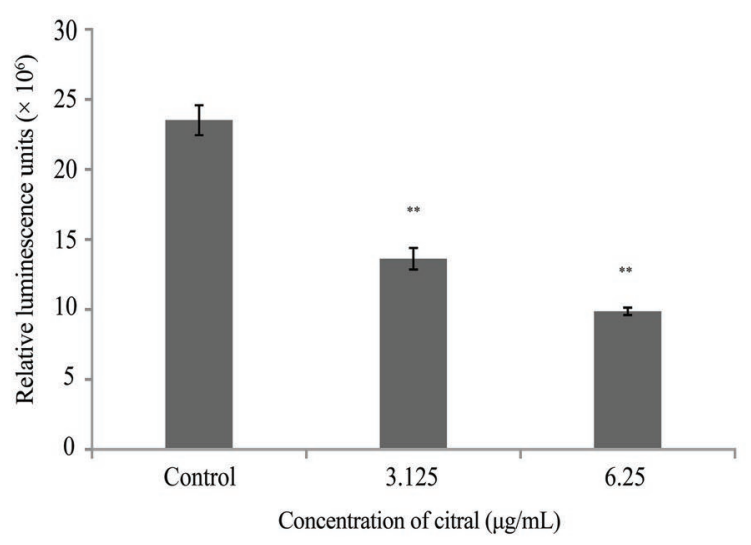

FIGURE 1 | (A) Growth of Vibrio parahaemolyticus ATCC 17802 treated with different concentrations of citral. Each value represents the average of three independent measurements. (B) Growth of Vibrio harveyi BB170 treated with different concentrations of citral. Each value represents the average of three independent measurements. (C) Inhibition of Al-2 production by Vibrio harveyi BB170 at sub-inhibitory concentrations of citral. Bars represent the standard deviation $(n=3) .{ }^{* *} p \leq 0.01$.

Among these, the most significant effects were observed following treatment with $12.5 \mu \mathrm{g} / \mathrm{ml}$ of citral, with greater than nine-fold decreases in flaA, luxS, and vp0950 transcription.

\section{DISCUSSION}

The global disease outbreaks and food contamination caused by $V$. parahaemolyticus underscore the importance of controlling the expression of virulence factors by this important foodborne pathogen. Citral has previously been shown to effectively control separate and specific virulence factors in different pathogens (Echeverrigaray et al., 2008; Ahmad et al., 2015). However, the effect of citral on virulence factors and antimicrobial resistance of $V$. parahaemolyticus still needs to be adequately investigated.

In previous studies, the MIC of citral was found to be $584 \mu \mathrm{g} / \mathrm{ml}$ for Cronobacter sakazakii (Shi et al., 2017), while curcumin inhibits $V$. parahaemolyticus and other Vibrio spp. with MICs exceeding $150 \mu \mathrm{g} / \mathrm{ml}$ (Packiavathy et al., 2013). In the current study, citral showed effective antibacterial activity against $V$. parahaemolyticus strains, with MICs ranging from 100 to $300 \mu \mathrm{g} / \mathrm{ml}$.

$V$. parahaemolyticus can alternate between two cell types depending on the growth conditions (Zhu et al., 2013). When grown in low viscosity and liquid culture, the cells appear as short rods with a single-sheathed polar flagellum, which is used for swimming and overcoming repulsive forces between the bacteria and the host tissues. However, when grown on solid surfaces and in high viscosity medium, the cells switch to a swarmer cell type and utilize their lateral flagellum to increase the surface tension, allowing them to aggregate and form a biofilm. FlaA, a specific polar flagellin, can mediate the formation of the flagellar filament, resulting in swimming motility (Loh et al., 2004). FlgL is the hook-associated protein 2 that plays an important role in polar flagellation and adhesion to host cells (Kim et al., 2008). FlgM is an anti- $\sigma$ factor, which can mirror the favorable conditions for swarming motility, resulting in an increase in flagellar filament numbers and switching the cell type to swarmer (Zhu et al., 2013). Echeverrigaray et al. (2008) demonstrated that citral effectively inhibited the swarming ability of Proteus mirabilis. In this study, citral effectively repressed both swarming and swimming motility of $V$. parahaemolyticus. Moreover, citral downregulated the transcription of flaA, $f l g L$, and $f l g M$. It was hypothesized that citral reduced the secretion of FlaA, FlgM, and FlgL, which impeded the ability of $V$. parahaemolyticus to recognize favorable attachment surfaces and the biosynthesis of polar and lateral flagella. Biofilm formation may be a major factor in the lowered shelf-life of $V$. parahaemolyticus-contaminated seafood and aid in the transmission of disease (Mizan et al., 2016). The CV assay showed that citral reduced the biofilm biomass of $V$. parahaemolyticus in a concentration-dependent manner at both 20 and $30^{\circ} \mathrm{C}$ within 3 days. A previous study showed that temperature influenced the production of EPS, which is related to biofilm formation (Garrett et al., 2008). In this study, the biofilm formation of isolate VP253 was decreased at $30^{\circ} \mathrm{C}$, possibly because the isolate was more sensitive to the high temperature. Moreover, citral caused greater biofilm biomass reduction of $V$. parahaemolyticus isolates VP244 and VP253 at $20^{\circ} \mathrm{C}$, while it showed more effective inhibition of biofilm formation by $V$. parahaemolyticus ATCC 17802 at $30^{\circ} \mathrm{C}$. It could be due to the fact that the optimal temperature for EPS secretion of $V$. parahaemolyticus ATCC 17802 might be $30^{\circ} \mathrm{C}$, while for the two other isolates, $20^{\circ} \mathrm{C}$ may be the optimal temperature. In line with the $\mathrm{CV}$ results, the FE-SEM images showed that 

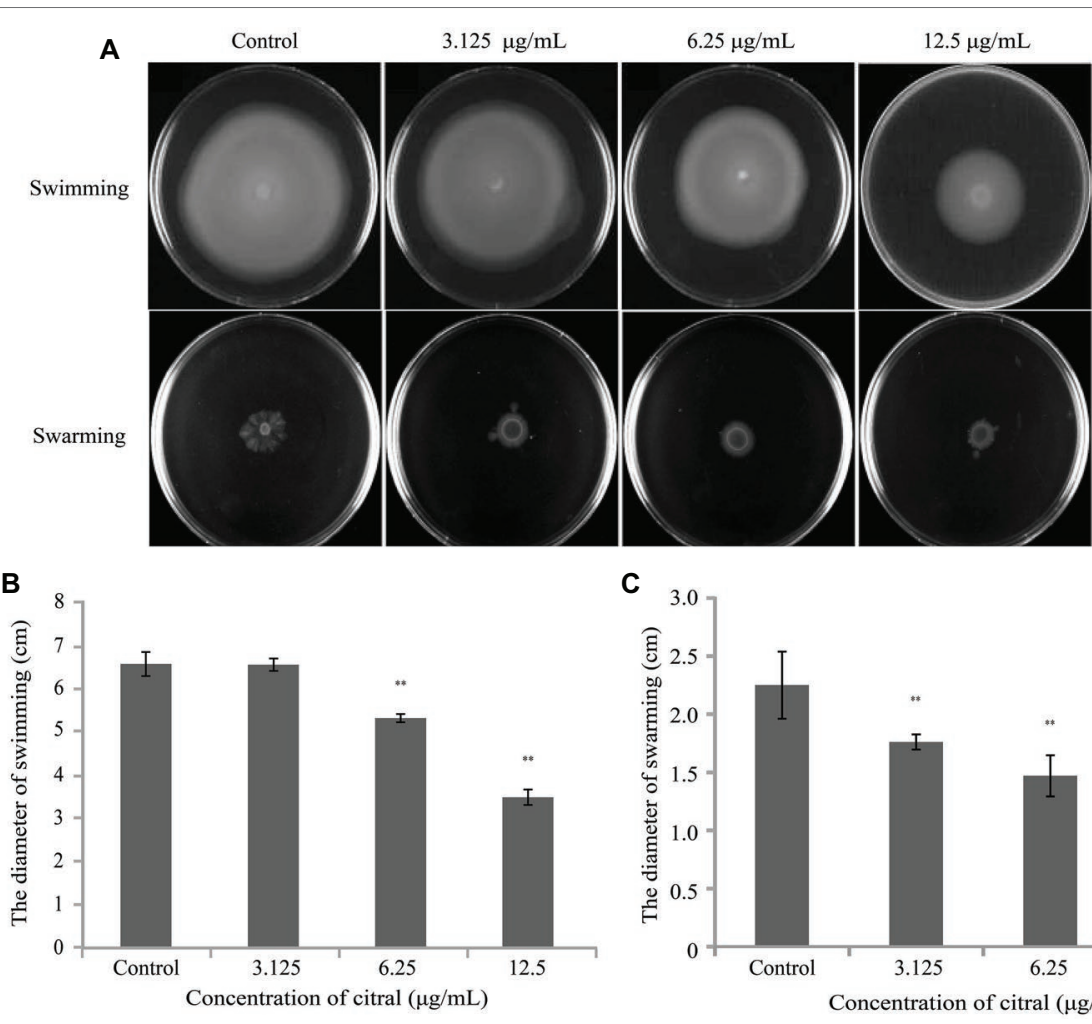

C

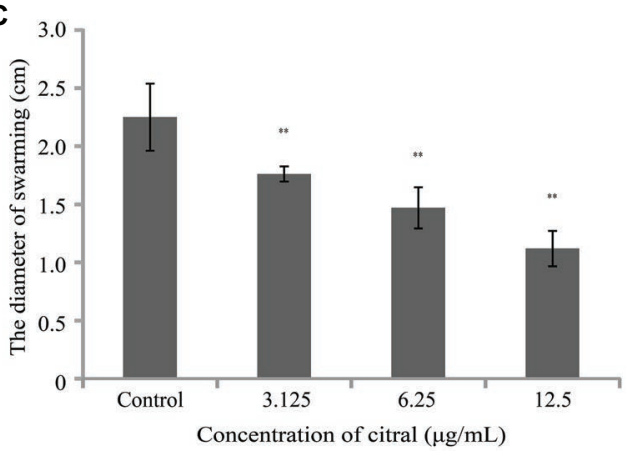

FIGURE 2 | (A) The effects of sub-inhibitory concentrations of citral on the swimming and swarming motility of Vibrio parahaemolyticus ATCC 17802.

(B) Measurement of $V$. parahaemolyticus ATCC 17802 migration in swimming motility assay. (C) Measurement of $V$. parahaemolyticus ATCC 17802 migration in swarming motility assay. The diameter is presented as the mean \pm the standard deviation of three independent experiments. ${ }^{\star \star} p \leq 0.01$.

the structure of the $V$. parahaemolyticus biofilm was obviously affected by the treatment of citral. The VP0950 (encoding a lipoprotein-related protein), VP0952, and VP0962 (encoding hypothetical proteins) were parts of biofilm (Boyd et al., 2008). The outer membrane proteins (OMPs) play an important role in nutrient uptake and in interactions with the environment and host tissues (Ritter et al., 2012). The transcription of $o m p W$ was related to the biofilm formation in Pseudoalteromonas sp. D41 (Ritter et al., 2012). In this study, citral impeded biofilm development of $V$. parahaemolyticus strains, possibly by damaging the biosynthesis of biofilm-associated proteins, repressing the expression of OMP-associated genes (such as ompW) and therefore the transportation of substances associated with the biofilm formation. Bacterial adherence to epithelial cell surfaces is a key stage in their survival and colonization of the gastrointestinal tract (Rasko and Sperandio, 2010). We found that the number of $V$. parahaemolyticus cells adhered to Caco-2 cells was decreased after pretreatment with citral. This finding is in agreement with the results of Shi et al. (2017), who showed that citral effectively inhibited the adhesion of $C$. sakazakii ATCC 29544 to Caco-2 cells. Additionally, Kirov (2003) reported that lateral flagella of Aeromonas strains caused persistent and dysenteric infections in the gastrointestinal tract. It was likely that the inhibition of flagella biosynthesis by citral contributed to the attenuation of $V$. parahaemolyticus adherence to Caco-2 cells.
T3SS1 effectors help $V$. parahaemolyticus to evade the host immune response, inducing autophagy followed by efficient lysis of the infected host cells, as well as causing cytotoxicity in host cells (Park et al., 2004). Among these effectors, VopQ causes rapid induction of autophagy in target cells, while VPA0450 destabilizes the cell by interfering with the association between the actin cytoskeleton and the cell membrane (Zhang and Orth, 2013). In this study, citral effectively downregulated the transcription of genes coding for the VopQ and VPA0450 effectors. As a result of citral-induced inhibition of these important effectors, $V$. parahaemolyticus might be more easily eliminated by the host immune response and find it more difficult to invade host cells. Additionally, flagella contain a sophisticated export apparatus involved in the secretion of several virulence factors that is closely related to type III secretion pathways (Kirov, 2003). The damage to the flagella structure caused by citral may influence type III secretion pathways, thereby impeding the delivery of effectors.

ToxR coordinately regulates several virulence-associated genes, including the tcp genes (toxin-coregulated pilus) and the ompU and ompT genes (major outer membrane proteins) in Vibrio cholerae (Lee et al., 2000; Childers and Klose, 2007). Moreover, $\mathrm{Vp}$-ToxR directly promoted the expression of $t d h 2$ and resulted in the development of Kanagawa phenomenon-positive virulent strains (Lin et al., 1993). Thermostable direct hemolysin (TDH) 

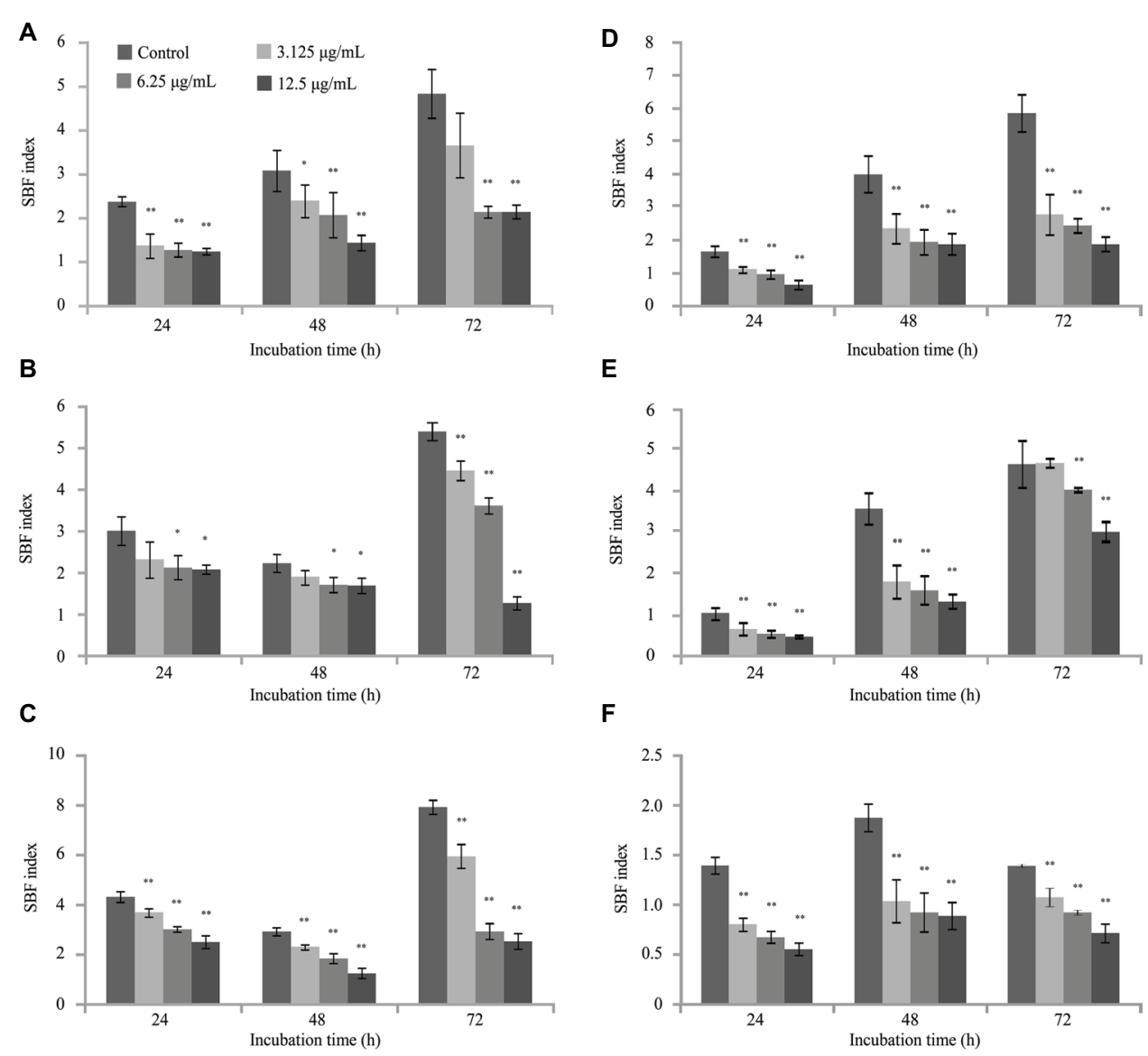

FIGURE 3 | The effects of citral on biofilm formation by Vibrio parahaemolyticus ATCC 17802 (A,D), VP244 (B,E) and VP253 (C,F) at $20^{\circ} \mathrm{C}$ (A-C) and $30^{\circ} \mathrm{C}$ (D-F). Bars represent the standard deviation $(n=3) .{ }^{*} p \leq 0.05,{ }^{* *} p \leq 0.01$.

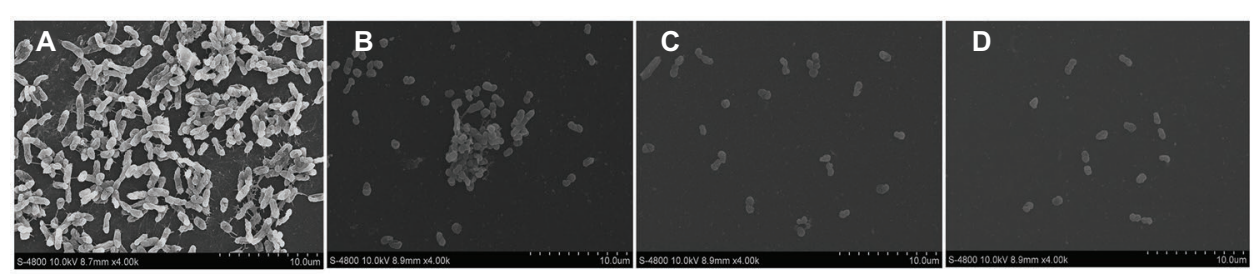

FIGURE 4 | The effects of SICs of citral Vibrio parahaemolyticus ATCC 17802 as observed by field-emission scanning electron microscopy (4,000 $\times$ magnification). (A-D) Control, $3.125 \mu \mathrm{g} / \mathrm{ml}, 6.25 \mu \mathrm{g} / \mathrm{ml}$, and $12.5 \mu \mathrm{g} / \mathrm{ml}$ citral, respectively.

is a protein toxin that has several biological functions, including hemolytic, enterotoxic, and cytotoxic activities (Lin et al., 1993). We observed that citral effectively downregulated the expression of toxR in $V$. parahaemolyticus, which possibly reduced the secretion of TDH or other toxins.

AI-2, a dihydroxy pentanedione-derived molecule synthesized by LuxS-like synthases, plays a role in inter-species communication in a wide variety of bacteria. At the low cell density, AphA is increasingly expressed to trigger the transcription of virulence genes which associated with infection (Wang et al., 2013). In this study, citral effectively repressed the biosynthesis of AI-2 and the transcription of $\operatorname{luxS}$ and aphA in $V$. parahaemolyticus. Similarly, a minimum citral concentration of $0.016 \mathrm{mg} / \mathrm{ml}$ inhibited QS by Pseudomonas aeruginosa (Ahmad et al., 2015). Low concentrations $(100 \mu \mathrm{mol} / \mathrm{L})$ of cinnamaldehyde were also effective at inhibiting AI-2-mediated QS in V. harveyi BB170 (Niu et al., 2006).

A luxS null mutation was reported to eliminate growth-phasedependent control of flaA in Helicobacter pylori and to downregulate flgM transcription in Escherichia coli K12 (Loh et al., 2004; Ling et al., 2010), while AphA is associated with the biofilm formation and motility in V. parahaemolyticus (Wang et al., 2013). 


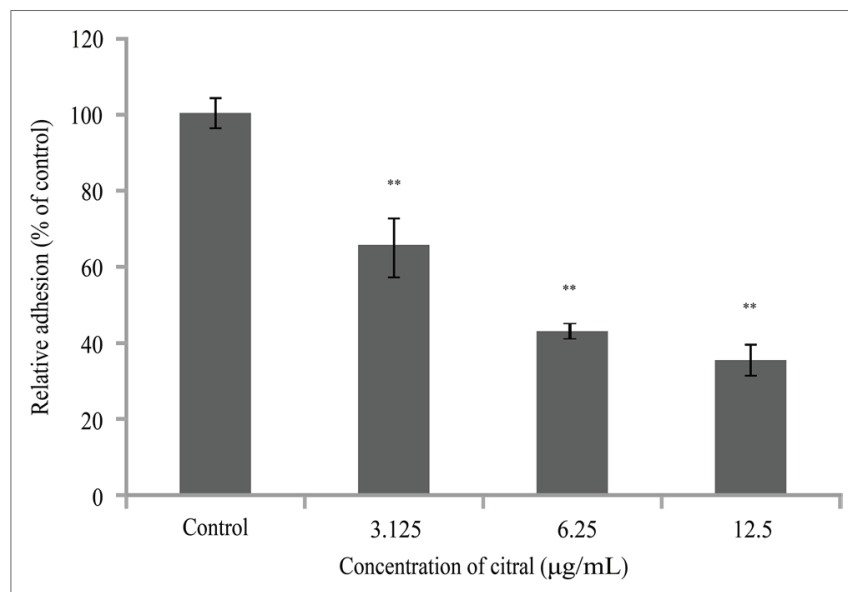

FIGURE 5 | The effects of sub-inhibitory concentrations of citral on adhesion of Vibrio parahaemolyticus ATCC 17802 to Caco-2 cells. Bars represent the standard deviation $(n=3) .{ }^{* *} p \leq 0.01$.

Moreover, QS appeared to repress ToxR-regulated virulence genes in $V$. cholerae (Zhu et al., 2002). In the present study, determining the effects of citral on multiple virulence targets could not exclude the influence of QS. The reduction of AI-2 may contribute to the changes in some traits during citral treatment, but whether it is the determining factor needs further investigation.

The growing emergence of antimicrobial-resistant $V$. parahaemolyticus becomes a challenge of controlling $V$. parahaemolyticus infections and food contamination (Xie et al., 2016). The OMPs (TolC and flagellin), transcription termination factor (NusA), ATP synthase F1, alpha subunit (F1-ATPa), and dihydrolipoamide dehydrogenase (DLD) were associated with AMP-resistance (Shen et al., 2010). This study showed that citral downregulated multiple AMP-resistant genes (tolC, nusA, atpA, dld and $f l a$ ) to various levels. It could be speculated that citral played a role in damaging the multidrug efflux transporter and membranes of $V$. parahaemolyticus, therefore reduced the resistance of $V$. parahaemolyticus.

\section{REFERENCES}

Adukwu, E. C., Bowles, M., Edwards-Jones, V., and Bone, H. (2016). Antimicrobial activity, cytotoxicity and chemical analysis of lemongrass essential oil (Cymbopogon flexuosus) and pure citral. Appl. Microbiol. Biotechnol. 100, 9619-9627. doi: 10.1007/s00253-016-7807-y

Ahmad, A., Viljoen, A. M., and Chenia, H. Y. (2015). The impact of plant volatiles on bacterial quorum sensing. Lett. Appl. Microbiol. 60, 8-19. doi: 10.1111/lam.12343

Amalaradjou, M. A. R., Kim, K. S., and Venkitanarayanan, K. (2014). Sub-inhibitory concentrations of trans-cinnamaldehyde attenuate virulence in Cronobacter sakazakii in Vitro. Int. J. Mol. Sci. 15, 8639-8655. doi: 10.3390/ijms15058639

Boyd, E. F., Cohen, A. L. V., Naughton, L. M., Ussery, D. W., Binnewies, T. T., Stine, O. C., et al. (2008). Molecular analysis of the emergence of pandemic Vibrio parahaemolyticus. BMC Microbiol. 8, 1-14. doi: 10.1186/1471-2180-8-110

Childers, B. M., and Klose, K. E. (2007). Regulation of virulence in Vibrio cholerae: the ToxR regulon. Future Microbiol 2, 335-344. doi: 10.2217/17460913.2.3.335

Chiu, T. H., Duan, J., Liu, C., and Su, Y. C. (2006). Efficacy of electrolysed oxidizing water in inactivating Vibrio parahaemolyticus on kitchen cutting

\section{CONCLUSIONS}

In conclusion, this investigation indicated that citral attenuated multiple virulence factors of $V$. parahaemolyticus, including QS, motility, biofilm formation, the adhesion to Caco-2 cells, and repressed the expression of genes related to flagella (polar and lateral), biofilm and T3SS1 effectors, virulence regulators (luxS, $a p h A$ and toxR), and AMP resistance. The results obtained in this work demonstrate the inhibitory effect of citral on virulence factors of $V$. parahaemolyticus. However, the data reported in this study only demonstrate the anti-virulence effect of citral in vitro. Further research is needed to clarify the mode of the antivirulence action of citral and to investigate its effects in experimental animal models, aiming toward the application of citral as an alternative strategy to control the infections of V. parahaemolyticus.

\section{AUTHOR CONTRIBUTIONS}

CS and YS conceived and designed the experiments. DG, ZH and HS performed the experiments. ZZ analyzed the data. XX contributed reagents, materials, and analysis tools. YS and CS wrote the manuscript.

\section{FUNDING}

This work was supported by the Fundamental Research Funds for the Central Universities (2452017228); National Natural Science Foundation of China (31772084); and General Financial Grant from the China Postdoctoral Science Foundation (2017M623256).

\section{ACKNOWLEDGMENTS}

We thank Dr. Baowei Yang and Dr. Guoyun Zhang in Northwest A\&F University for technical assistance, Dr Hongyu Tian in Beijing Technology and Business University for writing assistance.

boards and food contact surfaces. Lett. Appl. Microbiol. 43, 666-672. doi: 10.1111/j.1472-765X.2006.02006.x

Coutard, F., Lozach, S., Pommepuy, M., and Hervioheath, D. (2007). Real-time reverse transcription-PCR for transcriptional expression analysis of virulence and housekeeping genes in viable but nonculturable Vibrio parahaemolyticus after recovery of culturability. Appl. Environ. Microbiol. 73, 5183-5189. doi: 10.1128/AEM.02776-06

Echeverrigaray, S., Michelim, L., Delamare, A. P. L., Andrade, C. P., da Costa, S. O. P., and Zacaria, J. (2008). The effect of monoterpenes on swarming differentiation and haemolysin activity in Proteus mirabilis. Molecules 13, 3107-3116. doi: 10.3390/molecules 13123107

Garrett, T. R., Bhakoo, M., and Zhang, Z. (2008). Bacterial adhesion and biofilms on surfaces. Prog. Nat. Sci.-Mater. Int. 18, 1049-1056. doi: 10.1016/j. pnsc.2008.04.001

Han, N., Mizan, M. F. R., Jahid, I. K., and Ha, S. D. (2016). Biofilm formation by Vibrio parahaemolyticus on food and food contact surfaces increases with rise in temperature. Food Control 70, 161-166. doi: 10.1016/j.foodcont.2016.05.054

Henke, J. M., and Bassler, B. L. (2004). Quorum sensing regulates type III secretion in Vibrio harveyi and Vibrio parahaemolyticus. J. Bacteriol. 186, 3794-3805. doi: 10.1128/jb.186.12.3794-3805.2004 
Isman, M. B. (2000). Plant essential oils for pest and disease management. Crop Prot. 19, 603-608. doi: 10.1016/s0261-2194(00)00079-x

Kim, S. Y., Hong, H. Y., Rhee, J. H., and Chung, S. S. (2008). Roles of flagellar hook-associated proteins in Vibrio vulnificus motility and virulence. J. Bacteriol. Virol. 38, 1-10. doi: 10.4167/jbv.2008.38.1.1

Kirov, S. M. (2003). Bacteria that express lateral flagella enable dissection of the multifunctional roles of flagella in pathogenesis. FEMS Microbiol. Lett. 224, 151-159. doi: 10.1016/s0378-1097(03)00445-2

LaSarre, B., and Federle, M. J. (2013). Exploiting quorum sensing to confuse bacterial pathogens. Microbiol. Mol. Biol. Rev. 77, 73-111. doi: 10.1128/ mmbr.00046-12

Lee, S. E., Shin, S. H., Kim, S. Y., Kim, Y. R., Shin, D. H., Chung, S. S., et al. (2000). Vibrio vulnificus has the transmembrane transcription activator ToxRS stimulating the expression of the hemolysin gene vvhA. J. Bacteriol. 182, 3405-3415. doi: 10.1128/jb.182.12.3405-3415.2000

Letchumanan, V., Pusparajah, P., Tan, L. T.-H., Yin, W.-F., Lee, L.-H., and Chan, K.-G. (2015). Occurrence and antibiotic resistance of Vibrio parahaemolyticus from shellfish in Selangor, Malaysia. Front. Microbiol. 6:1417. doi: 10.3389/fmicb.2015.01417

Li, G. H., Wang, X., Xu, Y. F., Zhang, B. G., and Xia, X. D. (2014). Antimicrobial effect and mode of action of chlorogenic acid on Staphylococcus aureus. Eur. Food Res. Technol. 238, 589-596. doi: 10.1007/s00217-013-2140-5

Lin, Z., Kumagai, K., Baba, K., Mekalanos, J. J., and Nishibuchi, M. (1993). Vibrio parahaemolyticus has a homolog of the Vibrio cholerae toxRS operon that mediates environmentally induced regulation of the thermostable direct hemolysin gene. J. Bacteriol. 175, 3844-3855. doi: 10.1128/jb.175.12.3844-3855.1993

Ling, H., Kang, A., Tan, M. H., Qi, X., and Chang, M. W. (2010). The absence of the luxS gene increases swimming motility and flagella synthesis in Escherichia coli K12. Biochem. Biophys. Res. Commun. 401, 521-526. doi: 10.1016/j.bbrc.2010.09.080

Loh, J. T., Forsyth, M. H., and Cover, T. L. (2004). Growth phase regulation of flaA expression in Helicobacter pylori is luxS dependent. Infect. Immun. 72, 5506-5510. doi: 10.1128/iai.72.9.5506-5510.2004

Makino, K., Oshima, K., Kurokawa, K., Yokoyama, K., Uda, T., Tagomori, K., et al. (2003). Genome sequence of Vibrio parahaemolyticus: a pathogenic mechanism distinct from that of $V$. cholerae. Lancet 361, 743-749. doi: 10.1016/s0140-6736(03)12659-1

Mizan, M. F. R., Jahid, I. K., Kim, M., Lee, K.-H., Kim, T. J., and Ha, S.-D. (2016). Variability in biofilm formation correlates with hydrophobicity and quorum sensing among Vibrio parahaemolyticus isolates from food contact surfaces and the distribution of the genes involved in biofilm formation. Biofouling 32, 497-509. doi: 10.1080/08927014.2016.1149571

Naves, P., Del, P. G., Huelves, L., Gracia, M., Ruiz, V., Blanco, J., et al. (2008). Correlation between virulence factors and in vitro biofilm formation by Escherichia coli strains. Microb. Pathog. 45, 86-91. doi: 10.1016/j. micpath.2008.03.003

Niu, C., Afre, S., and Gilbert, E. S. (2006). Subinhibitory concentrations of cinnamaldehyde interfere with quorum sensing. Lett. Appl. Microbiol. 43, 489-494. doi: 10.1111/j.1472-765X.2006.02001.x

Packiavathy, I. A. S. V., Agilandeswari, P., Musthafa, K. S., Pandian, S. K., and Ravi, A. V. (2012). Antibiofilm and quorum sensing inhibitory potential of Cuminum cyminum and its secondary metabolite methyl eugenol against gram negative bacterial pathogens. Food Res. Int. 45, 85-92. doi: 10.1016/j. foodres.2011.10.022

Packiavathy, I. A. S. V., Sasikumar, P., Pandian, S. K., and Veera Ravi, A. (2013). Prevention of quorum-sensing-mediated biofilm development and virulence factors production in Vibrio spp. by curcumin. Appl. Microbiol. Biotechnol. 97, 10177-10187. doi: 10.1007/s00253-013-4704-5
Park, K. S., Ono, T., Rokuda, M., Jang, M. H., Okada, K., Idia, T., et al. (2004). Functional characterization of two type III secretion systems of Vibrio parahaemolyticus. Infect. Immun. 72, 6659-6665. doi: 10.1128/ iai.72.11.6659-6665.2004

Rasko, D. A., and Sperandio, V. (2010). Anti-virulence strategies to combat bacteria-mediated disease. Nat. Rev. Drug Discov. 9, 117-128. doi: 10.1038/ $\operatorname{nrd} 3013$

Ritter, A., Com, E., Bazire, A., Goncalves, M. D., Delage, L., Le Pennec, G., et al. (2012). Proteomic studies highlight outer-membrane proteins related to biofilm development in the marine bacterium Pseudoalteromonas sp D41. Proteomics 12, 3180-3192. doi: 10.1002/pmic.201100644

Shen, C. J., Kuo, T. Y., Lin, C. C., Chow, L. P., and Chen, W. J. (2010). Proteomic identification of membrane proteins regulating antimicrobial peptide resistance in Vibrio parahaemolyticus. J. Appl. Microbiol. 108, 1398-1407. doi: $10.1111 /$ j.1365-2672.2009.04544.X

Shi, C., Sun, Y., Liu, Z., Guo, D., Sun, H., Sun, Z., et al. (2017). Inhibition of Cronobacter sakazakii virulence factors by citral. Sci. Rep. 7:43243. doi: 10.1038/srep43243

Wang, L., Ling, Y., Jiang, H., Qiu, Y., Qiu, J., Chen, H., et al. (2013). AphA is required for biofilm formation, motility, and virulence in pandemic Vibrio parahaemolyticus. Int. J. Food Microbiol. 160, 245-251. doi: 10.1016/j. ijfoodmicro.2012.11.004

Wojtyczka, R. D., Orlewska, K., Kepa, M., Idzik, D., Dziedzic, A., Mularz, T., et al. (2014). Biofilm formation and antimicrobial susceptibility of Staphylococcus epidermidis strains from a hospital environment. Int. J. Environ. Res. Public Health 11, 4619-4633. doi: 10.3390/ijerph110504619

Wu, Y., Wen, J., Ma, Y., Ma, X., and Chen, Y. (2014). Epidemiology of foodborne disease outbreaks caused by Vibrio parahaemolyticus, China, 2003-2008. Food Control 46, 197-202. doi: 10.1016/j.foodcont.2014.05.023

Xie, T., Xu, X., Wu, Q., Zhang, J., and Cheng, J. (2016). Prevalence, molecular characterization, and antibiotic susceptibility of Vibrio parahaemolyticus from ready-to-eat foods in China. Front. Microbiol. 7:549. doi: 10.3389/ fmicb.2016.00549

Yeung, P. S. M., Hayes, M. C., DePaola, A., Kaysner, C. A., Kornstein, L., and Boor, K. J. (2002). Comparative phenotypic, molecular, and virulence characterization of Vibrio parahaemolyticus O3: K6 isolates. Appl. Environ. Microbiol. 68, 2901-2909. doi: 10.1128/aem.68.6.2901-2909.2002

Zhang, L., and Orth, K. (2013). Virulence determinants for Vibrio parahaemolyticus infection. Curr. Opin. Microbiol. 16, 70-77. doi: 10.1016/j. mib.2013.02.002

Zhu, S. W., Kojima, S., and Homma, M. (2013). Structure, gene regulation and environmental response of flagella in Vibrio. Front. Microbiol. 4:410. doi: 10.3389/fmicb.2013.00410

Zhu, J., Miller, M. B., Vance, R. E., Dziejman, M., Bassler, B. L., and Mekalanos, J. J. (2002). Quorum-sensing regulators control virulence gene expression in Vibrio cholerae. Proc. Natl. Acad. Sci. U.S.A. 99, 3129-3134. doi: 10.1073/ pnas.052694299

Conflict of Interest Statement: The authors declare that the research was conducted in the absence of any commercial or financial relationships that could be construed as a potential conflict of interest.

Copyright (c) 2019 Sun, Guo, Hua, Sun, Zheng, Xia and Shi. This is an open-access article distributed under the terms of the Creative Commons Attribution License (CC BY). The use, distribution or reproduction in other forums is permitted, provided the original author(s) and the copyright owner(s) are credited and that the original publication in this journal is cited, in accordance with accepted academic practice. No use, distribution or reproduction is permitted which does not comply with these terms. 